\section{figuration and the \\ child}

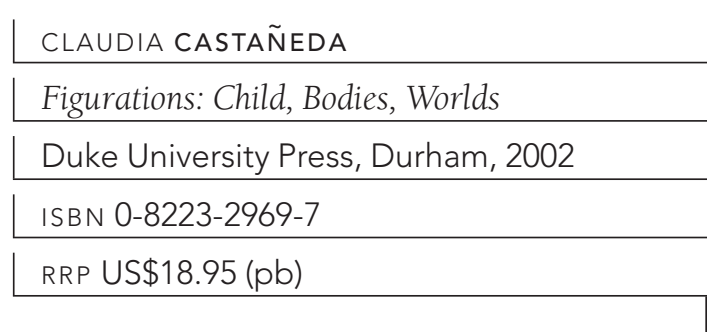

Claudia Castañeda has written a really wonderful book, which I recommend to all those interested not only in the cultural analysis of childhood, but also in understanding how this might be related to postcolonial cultural theory more generally. This book seeks to provide the basis for a theorisation of childhood that moves beyond the idea of the child as a potential adult, an entity in the making, to think about the way in which the child comes to accrue 'significant cultural value'. Castañeda argues that precisely because the child is malleable, by definition a subject who is in flux, changing, growing, the child is never stable or complete in itself. It is this very incompleteness that allows the child to figure within a number of significant cultural fields in relation to issues that are of profound significance for children and adults.

To develop her argument, Castañeda employs the concept of figuration. She explores the material and semiotic practices that bring the figure of the child into being at any particular moment, in any particular place. In doing so, she argues that what is claimed as the most universal aspects of being a child are themselves local and specific. While this idea of specificity and locality is not new in itself, the way that Castañeda uses it to understand the specificity of the local-global as figured within particular debates allows us, in particular, to think about the place of the local within the global, and how the national is always figured within transnational circuits of exchange. She explores this through a number of impressive case studies, which highlight these circuits of exchange in a way hitherto quite underdeveloped within the field of childhood studies. 
These case studies involve, first of all, developmentalism and nineteenth-century science. This is by now quite a well-trodden path, in that the idea of psychological development as a universal process is a story that emerges out of specific discourses within the natural sciences to create a universal model of psychological development. Such discourses read colonial Others through a developmental narrative that understood various 'natives' and 'savages' as less developed or childlike, through an account of normality and pathology. This analysis sets up the relation Castañeda wishes to establishnamely that, historically, European grand narratives of the child have created a figure that acts as a way not only of understanding children all over the world but also of explaining difference in terms of Other adulthoods being read back as childlike. In twenty-first-century figurations, therefore, this history is always already present, such that any European or US understanding of the developing child always carries with it a set of Others, both children and adults, subsumed within it.

The second example explored by Castañeda is figurations of the child within contemporary neuro-behavioural sciences. Understandings of the brain's plasticity during a particular 'critical period' have been interpreted within AngloAmerican neuroscience as providing the basis for critical interventions in which the adult to be can be shaped by specific input from parents, so that American middle-class parents are enjoined by science journalists drawing upon this research to provide the kind of stimulation that will pattern the child's brain to become the successful middle-class adult. Culture in this analysis is something that acts upon development, and that shapes the child into the adult it could become or is prevented from being. The child is potential, the potential to become the embodiment of the American middle-class way of life, understood as a universalised and normalised process.

However, this figure of the child as potential contains another figure, one Castañeda does not explore. That figure is the parent, or I think, more specifically, the mother. It is the middleclass American mother who bears the responsibility for the development of this potential and who must therefore herself be the target of a myriad normalising judgements, which equally, though differently, police her Othered counterparts. I would argue that there is a long history in which the mother is made to be the figure who is responsible for the normal development of her child, without whom development cannot be taken to happen properly. ${ }^{1}$ Thus, the figure of the child not only stands for potential, as Castañeda argues, but it is also, I suggest, the proto-masculine subject, whose proper emergence as a civilised adult is made the task of femininity. I argue that this maternal figure is always a shadowy presence around the figure of the child, which ensures that the potential the child represents is the future of civilised masculinity to which the woman is always positioned as subservient.

The figure of the mother emerges more clearly in Castañeda's third and fourth examples - those of American discourses around transnational adoption, particularly between the USA and Latin America, and rumours of child organ stealing in Latin America. Here, of course, 
there are two mothers-the US mother who adopts and the Latin American mother who loses her child. Castañeda shows skilfully how the grieving mother who loses her child is a central trope within post-conquest narratives. She argues that we should understand adoption as a reproductive technology, since transnational adoption is for many Western women the last possibility of having a baby when reproductive technologies have not worked. Thus, the child becomes a commodity in the complex circuit of exchange between the Third World and the First, between poverty and plenty and one kind of motherhood and another. This circuit of exchange is occluded by an American multiculturalism that understands transnational adoption as the possibility of creating families of difference. Occluded also is the specificity of the Western infertile woman and the specific circuits of exchange in which she is figured. However, an address to the commodified Third World child, the new cargo, would allow us to understand how to separate that child's subjectivity from the two lost and grieving mothers and therefore engage with the particularity of what it means to be that child.

Castañeda also explores rumours of child organ theft from Latin America by US Americans. This allows her to develop her argument about the circuits of exchange into which the Latin American child enters. Within these rumours, the child is not even a whole body, but is dismembered into parts—-killed for shipping to the hospitals of the wealthy. Castañeda's analysis of the political situation in Guatemala brings the importance of analysing the circuits of exchange into sharp focus.
Castañeda's final discussion relates to figurations of the child within feminist theory, including my own work. She demonstrates powerfully how certain theoretical tropes mean an evasion of the engagement with the specificity of situated practices in which the child is constituted. In relation to my own work, she argues that I do not explore the way in which my privileged status as an adult allows me to makes theorisations of child subjectivity that have been compromised by the fact that the child has been constituted as 'the adult's presubjective other'. In other words, she is suggesting that because I explore the memory of my own fantasies as a child in my reading of the children who are the objects of my narrative, I always read their stories back through a narrative of potentiality, where the object of interest is the adult woman (me) who has to be explained and not the child herself. I think that Castañeda is making a valuable point, which allows us to think about the importance of explanatory frameworks in which the child acts as a point in circuits of exchange produced within local and specific situated discursive practices.

However, for me she raises another more difficult methodological point. That is, the complex relation between our own subjectivities and the focus of our research. What are the stories we want to tell and why? What is our emotional connection to the issues and children we research? While Castañeda shows brilliantly how the figure of the child is constituted within local-global circuits of exchange, it is as though she had no emotional relation to the material other than to demonstrate the 
problems with existing accounts. This suggests that we are still in the terrain of academic disinterest and objectivity, which is so much critiqued by the feminist approaches to science to which Castañeda alludes. The circuits of exchange in which children live are not simply rational connections within specific practices, but are deeply emotional relations, full of pools and eddies. How then to develop work that is able to incorporate, embody, this complex emotionality within the specificity of local practices and the global circuits of exchange within which those practices exist? Castañeda shows us that the child figure is so often used as a trope for talking about something else because, as she says, the child is by necessity in a process of flux and transformation. Perhaps this flux itself obscures the apparent stasis with which the adult is viewed as somehow having completed all transformations through the achievement of adulthood. By this I do not mean that we should be aware of 'lifespan development', but we could examine how the focus on the child also carries with it the implicit message that change and transformation are simply the province of those we designate as children and that we commonly use developmental metaphors to understand the twists and turns of adult lives.

It is not simply, as Castañeda says, that we talk now of returning to heal our inner child, but that we have barely any way of talking about change and transformation within adult subjectivity that does not in fact depend upon its other, the child and a return to childlike and earlier states of development to understand shifts and changes in the adult. Thus, it is not simply that the child is understood as a potential adult but that the adult is understood as having gone beyond childhood. Thus adult and child form a couple, where one cannot exist without the other. What would it mean then to take apart the shaky foundation of difference on which both adult and child are constituted? Castañeda's important book takes us on the first steps of a path that might help us to explore that crucial issue.

Valerie Walkerdine is Foundation Professor of Critical Psychology at the University of Western Sydney.

1. Valerie Walkerdine, The Mastery of Reason, Routledge, London, 1988; Valerie Walkerdine and Helen Lucey, Democracy in the Kitchen: Regulating Mothers and Socialising Daughters, Virago, London, 1989. 